\title{
Alguns Aspectos do Sistema de Pessoal
}

\author{
Marcelino Ferreira Bastos
}

$\mathrm{O}$

ano passado, fui convidado pelo DASP para dar um curso de legislação de pessoal. As minhas primeiras palavras aos colegas foram: não ser professor de legislação e que me apresentava, apenas, como um funcionário com experiência em assuntos de pessoal, com mais de 20 anos de serviço nesse assunto e aceitava a incumbência, mais como uma homenagem a Brasília. E faço isso, por entender que nós, em Brasilia, precisamos pensar menos em têrmos de transferência da Capital e pensar mais em têrmos de consolidação da Capital. Quer dizer, podemos melhorar nossa infra-estrutura cultural em Brasilia e com isso recrutar, para o serviço público, tôdas as pessoas capacitadas, aproveitar a juventude que está saindo das escolas e que pode dar uma cota de sacrifício ao país muito maior do que a nossa geração.

E com êsse intuito que me apresento aos senhores, não só com uma experiência de mais de 20 anos em assuntos de pessoal.

O tema que me foi dado é de sistema de pessoal. Tema vasto. Sistema é um conjunto de órgãos. Em física, sistema de fôrças é um conjunto de fôrças atuando em determinado sentido. Sistema de Orçamento é um conjunto de órgãos atuando para formar um plano de trabalho do Govêrno. Sistema de pessoal é um conjunto de órgãos objetivando administrar o pessoal. $O$ objetivo principal de um sistema de pessoal é fazer os órgãos funcionarem com a maior produtividade, com o menor gasto e no menor tempo. É êste o objetivo final de uma administração de pessoal.

Os instrumentos de uma administração de pessoal são, em primeiro lugar, uma boa classificação de cargos. Esse tema, no Brasil, ainda é pouco conhecido e até mesmo a nossa realidade não aconselha a implantação de um plano perfeito, mas nos países adiantados, mais desenvolvidos, o sistema de classificação de cargos é um dos principais instrumentos de administração de pessoal. 
Basta atentar para o seguinte fato - um pedreiro tem sua atribuição diferente de um servente de pedreiro. A classificação de um cargo de pedreiro é, portanto, diversa da de servente. Dentro da nossa realidade temos que trabalhar com os instrumentos de trabalho que possuimos. Nem sempre podemos aplicar uma classificação de cargos. Nem podemos, às vêzes, recrutar, também, pessoal capaz para êsse cargo. Recordo-me de um amigo que estêve na França visitando o Museu do Louvre, e viu, ali, dar-se aulas a operários em construção. Creio que até os nossos engenheiros não têm um treinamento equivalente. Também dentro da administração pessoal a nossa falha é imensa, mas não há dúvida nenhuma de que um plano de classificação de cargos é um dos instrumentos, um dos mais perfeitos, para qualquer administrador nos países bem organizados e adiantados, como almejamos que seja o Brasil algum dia.

Nosso atraso é muito grande, em todos os aspectos, principalmente na administração de pessoal. Esta é, em sintese, a explicação técnica do que seja sistema de pessoal: vários órgãos trabalharido no sentido de recrutar, selecionar e aperfeiçoar pessoal capaz para desempenhar as atividades de determinados órgãos. Pela reforma administrativa o DASP é o órgão de cúpula do sistema, funcionando conjunta e harmoniosamente com os órgãos de pessoal dos Ministérios.

Qual a obrigação dos funcionários que compõem um órgão de pessoal?

É a de fazer cumprir as leis traçadas sôbre pessoal, a política traçada pelo Govêrno, pelos administradores.

Para que o órgão de pessoal se capacite e esteja em condições de assessorar o administrador que, muitas vêzes, desconhece êsses assuntos e que tem outras tarefas muito mais importantes ou, mesmo que não sejam mais importantes, mais especializadas.

Como o caso da SUDECO - seu administrador não pode estar se preocupando com assuntos de pessoal. Ele quer organizar o seu plano de trabalho e quer pessoal capaz para executá-lo. Cabe ao órgão de pessoal, então, a incumbência do recrutamento, e da seleção, que, dentro do regime democrático, deve ser através de concursos, não só por uma exigência de ordem constitucional, mas porque faz parte das declarações dos Direitos do Homem dar oportunidade a todo cidadão de poder participar da administração de seu país.

Isso não significa que o concurso seja público. Pode ser através de entrevista, pode ser outro modo onde se implante um 
sistema de pessoal bem organizado. Na América do Norte, por exemplo; o órgão de pessoal faz o recrutamento, seleciona, faz as provas. Não há uma obrigatoriedade de nomeação por ordem de classificação. Há, também, uma certa perplexidade, um desconhecimento disso, dada a natureza de país subdesenvolvido. Um país como o nosso, subdesenvolvido, onde há pouca oferta de empregos, faz-se sôbre o Estado as maiores pressões para conseguir emprêgo para o pessoal que não tem outros meios de vida. Daí a razão por que não é possivel implantar-se $11 \mathrm{~m}$ sistema de pessoal baseado na experiência de outros povos. Temos de qualquer maneira de trabalhar com a nossa realidade. A nossa realidade é essa, infelizmente. Tive oportunidade, durante as minhas aulas, de sempre procurar ensinar a legislação, procurando interpretá-la de acôrdo com a realidade objetiva. A atribuição principal dos funcionários dos órgãos de pessoal é fazer aplicar a legislação. como ela se encontra, sem discutir se é justa ou injusta. Porque a modificação dessa justiça ou injustiça compete aos Podêres competentes - o Legislativo e o Executivo.

Diante disso, parto, então, para o ensino da legislação, procurando analisar qual a relação existente entre uma norma legal e uma realidade nossa. Com isso, procuro, às vêzes, despertar interêsse dos próprios alunos e surgir outras modificações das leis. Mas, de qualquer maneira, dentro do Poder Executivo nos órgãos de pessoa!, temos a bbrigação de aplicar a lei tal como ela é; procuro desenvolver o ensino de legislação dentro dessa realidade e tenho obtido sucesso. Darei alguns exemplos de como procurei ensinar. Depois ficarei à disposição dos senhores para algumas perguntas.

Tôda lei guarda uma relação com uma realidade. Quando ela não guarda essa relação, essa lei é violada (ela é até desconhecida). Citarei dois exemplos recentes de fatos que surgiram antes da lei. Um fato - transplante de coração. Tôda a norma legal surge em conseqüência de um fato real, um fato que pode ser de natureza politica, interna ou externa, pode ser de natureza técnica ou científica, enfim, um fato de natureza social. Antes de se regulamentar o transplante do coração, primeiro surgiu o fato, depois é que se teve o cuidado de regular o transplante.

Mesmo assim, o próprio poder da ciência teve o cuidado de não contrariar outros podêres de decisão e, por essa razão, o primeiro transplante de coração só foi possivel num hospital não assistencial.

Outro exemplo não mais de surgimento da lei, mas de desrespeito ou desconhecimento da lei. A exploração do petróleo das 
nossas plataformas continentais, por emprêsas nacionais e estrangeiras. Todos nós sabemos que há uma lei dando à Petrobrás o monopólio estatal do petróleo, e no entanto, um mero decreto dá concessões a emprêsas nacionais ou estrangeiras para exploração da nossa plataforma continental.

É evidente que não tenho conhecimento, nem me cabe analisar, quais são os podêres que influiram num ato dessa natureza. Como estudioso em matéria de pessoal, só posso citar um dos fatôres que contribuiram para isso - é a política de pessoal implantada pela Petrobrás. Um órgão criado pelo Govêrno, com recursos arrecadados da população, recursos, em última instância do Tesouro, implanta uma política salarial, muitas vêzes superior às dos órgãos da máquina administrativa permanente do Estado, pois os seus funcionários recebem 17 meses de salários por ano. Então, é bem possivel que, se a Petrobrás tivesse uma política de pessoal mais condizente com a nossa realidade, ou aplicasse uma politica salarial de acôrdo com o mercado de trabalho geral do Brasil, ela hoje talvez tivesse recursos próprios para fazer a exploração da nossa plataforma continental e com isso aumentaria nossa riqueza.

À vista dêsses exemplos, procuro ensinar legislação, comparando-a com uma realidade, procurando ver uma correspondência com um fato real. Darei, como exemplo, a questão da posse. Os requisitos para a posse no cargo público. Estamos observando, hoje, uma tendência a terminar com o funcionário público e implantar o regime de legislação trabalhista. Não acredito que isto solucionará o problema e não acredito porque posso citar outros exemplos.

A Companhia Siderúrgica Nacional produz o aço mais caro do mundo, e é por causa da política de pessoal exclusivamente excesso de pessoal, apesar de regido pela C.L.T., salário muito mais alto do que o do mercado de trabalho equivalente. No serviço público vai acontecer a mesma coisa com a legislação trabalhista e continuaremos com os mesmos ranços de funcionários públicos. Acho que o que temos de modificar um pouco é a mentalidade da população, mentalidade dos nossos dirigentes, e até mesmo do sistema educacional, pois todos nós, pelo menos na classe média, somos educados mais para o aprendizado contemplativo do que para o trabalho.

Não é só a classe média. O próprio operário também não é educado para o trabalho, porque, se o operário tiver consciência de que o aumento de produtividade de sua fábrica resulta sempre em benefício dêle ou da coletividade, êle procura também melhorar 
a produtividade dessa fábrica. Se um industrial, dono de uma emprêsa, ver aumentada a sua produtividade e conseqüentemente a sua riqueza, três fatos podem acontecer: êle pode vender os seus produtos mais baratos aos consumidores, pode dar aumento de salário aos seus empregados ou ampliar sua emprêsa e, com isso, oferecer novos empregos. Então, a educação também deve ser modificada para tôda a população. Educar o povo para o trabalho. Infelizmente, nas nossas escolas não ensinam esta verdade elementar. Em Brasília já foi feito um levantamento sôbre as crianças que freqüentam a Escola Parque, que desde o início são educadas para o trabalho; estudam de manhã, de tarde têm outro trabalho manual; elas, ao ingressarem no ginásio se desenvolvem muito mais rápido do que as demais crianças e têm muito mais noção de responsabilidade do que as outras; muito menos preguiça para fazer educação física.

Então é falha de educação. O nosso povo é educado para não trabalhar e para dar golpes e arranjar emprêgo público, para não ter chefe nem patrão. E' uma falha mais de educação, que leva ao abuso de direitos. Vocês sabem que a nossa Marinha Mercante quase foi destruída pelo abuso dos direitos. Chegou a um tal ponto que um simples mestre, daquelas barcas do Rio a Niterói, ganhava mais que um comandante da esquadra brasileira. Êsse abuso, além de se enxergar no Estado uma entidade mágica, que tudo pode fazer, e de não querer trabalhar, levou à destruição da classe dos marítimos e a quase destruição da Marinha Mercante. Acredito que a implantação de um sistema de pessoal só será possivel quando se modificar essa mentalidade. É a mentalidade que talvez só outra geração possa melhorar. De qualquer maneira, são problemas que estamos levantando e essa outra geração que vier, pelo menos fique sabendo que debatemos êsse problema. Feito isto, é preciso que, para a implantação dêsse sistema de pessoal, os funcionários que trabalham nos serviços de pessoal apliquem a législação, assessorem o seu chefe, que, muitas vêzes, é um técnico de outra especialidade e que nunca tomou conhecimento a respeito de leis. Nenhum país pode viver sem organização e sem lei. Naturalmente, que não deve ser excesso de lei, fora da realidade. A lei determina que seja o DASP o órgão de cúpula da administração de pessoal, que faça sistema de classificação de cargos, que oriente os demais órgãos do sistema e que fiscalize. Recentemente, saiu um decreto. Pela primeira vez vi um decreto criando uma comissão com a incumbência até de fazer classificação de cargos, e de dois membros. Um membro do Ministério da $\mathrm{Fa}$ zenda e outro do Ministério do Planejamento. Então, não há ninguém para desempatar? Quem redigiu êsse decreto nada en- 
tende de legislação de pessoal e não tem a mínima noção da realidade brasileira.

Essas são as minhas palavras iniciais sôbre sistema de pessoal em si, como matéria de organização e como objetivo de administração de pessoal. Naturalmente que isto envolve os mais variados problemas. Como selecionar, como recrutar, como preparar as chefias, como treinar o pessoal dentro de sua repartição, como colocar o homem próprio para o lugar certo. Selecionar quais são aquêles que podem ou não trabalhar com o público, quais aquêles que são incapazes de ficar meia hora sentados, se êles são irrequietos? Qual será o seu melhor campo de atividade? Esses são problemas de ordem técnica e que demandaria maior tempo para explanação. Se nós vamos tratar de pessoal, vamos fazer uma equipe de pessoal conhecedora da matéria. Vou dar um exemplo de como procurei ensinar legislação sem a preocupação de gravar, de decorar. Citei, por exemplo, o caso de posse. Naturalmente, acho, hoje, a posse ultrapassada. Considero até uma reminiscência do mandarinato. Parece apenas necessária a posse em cargos de direção, a exemplo do que se faz nas corporações militares em que o comandante passa em revista a sua tropa para que os soldados o conheçam. Então, é natural que o dirigente de um órgão tome posse para que os funcionários dêsse órgão fiquem conhecendo o e lhe dêem o devido respeito. Mas, ao funcionário comum me parece ultrapassado êsse requisito de posse. Mas, de qualquer maneira, é uma exigência da lei e como somos do executivo temos de cumpri-la, como ela é. Vou dar exemplo, como eu procurei ensinar, quais são os requisitos para uma posse.

Para que os funcionários compreendam, sem a preocupação de decorar - ter completado 18 anos de idade. A que fato real corresponde 18 anos? Então eu procurei dar uma outra relação. $\mathrm{E}$ a mulher, ela não pode se casar com 16 anos? Existirá maior responsabilidade para uma mulher do que contrair família? Conceber? Penso que não. Então, se a mulher tem condições, talvez, de ordem fisiológica, condições de contrair família e formar o seu lar aos 16 anos, ela também pode tomar posse. Pode também exercer os seus direitos políticos. É uma exigência de ordem constitucional a idade. Há outra condição para tomar posse - é a de ser brasileiro. Então, eu coloco no quadro-negro - Brasileiro nato - está certo? Alguns respondem que sim e outros não. O Estado quando institucionaliza, êle visa, enfim, à defesa e ao bem-estar de determinada comunidade. Logo, se a máquina administrativa é mantida para servir a essa comunidade é lógico que seja um brasileiro possa exercer um dêsses cargos. Mas, se um 
estrangeiro vem para aqui e resolve integrar essa comunidade, satisfaz todos os requisitos que a lei exige, para a integrar, não vejo razão por que também não dar a êle oportunidade de servir ao país onde se encontra e de ocupar um cargo público. A propósito disso cito um fato que ocorreu. O Presidente Castelo Branco deu uma aula inaugural na Escola Superior de Guerra e numa das mais profundas análises da situação política nacional e internacional que já li êle teve a oportunidade de mostrar o equilibrio de terror, formado entre as duas grandes potências. E êsse fato gerando naturalmente dois consensos, o consenso oriental e o consenso ocidental e por tôdas as razões estamos dentro do consenso ocidental.

Através de uma dialética exuberante e empregando princípios de estratégia que só êle mesmo seria capaz de fazer, concluiu no sentido de que havia conveniência para admissão de tropas estrangeiras dentro do país. Então, diante dêsse fato procurei alertar o aluno: se nós podemos ter em nossas bases cargos militares ocupados por estrangeiros, não ficarei surprêso se amanhã o tivermos cargos civis ocupados por estrangeiros. Naturalmente, que essa minha observação foi mais para não tornar a aula monótona. Procurando, ainda, filosofar, se é que a tanto posso me atrever, verifiquei que êle também no seu comentário chamava atenção para a existência de dois dissensos. Depreendia-se que era o dissenso da França, no mundo ocidental, e o dissenso da China no mundo comunista. Naquela oportunidade almejei que êsses dissensos se multiplicassem de ambos os lados, de forma a surgir um só consenso. Os fatos vieram realmente confirmar a existência de novos dissensos. Mas, todos, infelizmente, obrigados a voltarem aos seus consensos. 